\title{
РЕЦЕНЗИИ
}

УДК 821.161.1.09

DOI: $10.17223 / 24099554 / 3 / 11$

\section{В.С. Киселев}

«...ВЕЧНАЯ, НЕУМИРАЮЩАЯ, НЕРАЗРУШИМАЯ ИТАЛИЯ»

(Рецензия на книгу: Лебедева Ольга, Янушкевич Александр. Образы Неаполя в русской словесности XVIII - первой половины XIX веков / ред. М. Капальдо, А. Д'Амелия. Салерно, 2014. 436 с.)

Статья посвящена исследовательской концепции новой монографии Ольги Лебедевой и Александра Янушкевича о русской литературной рецепции Неаполя. Акиентируется внимание на оригинальных методологических подходах $к$ реконструкции имагологического образа. Оиенивается значимость выявленных авторами доминант в мифопоэтическом, природно-ландшафтном, антропологическом и культурно-историческом плане русской неаполитань ХVIII-начала XX в.

Ключевые слова: история русской литературы, имагология, Италия, Неаполь, русско-итальянские литературные связи.

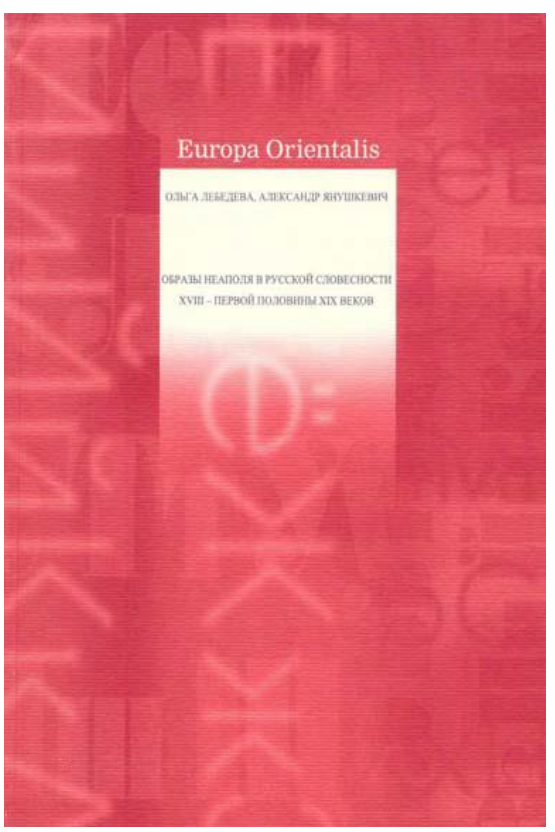

В русском культурном сознании Италия занимает особое место, определяемое ощущением глубинного родства. Вряд ли можно найти более точные слова для его выражения, чем это сделал в начале XX в. Н.А. Бердяев: «Русская тоска по Италии - творческая тоска, тоска по вольной избыточности сил, по солнечной радостности, по самоценной красоте. <...> Италия обладает таинственной и магической силой возрождать душу, снимать тяжесть с безрадостной жизни. Такова вечная, 
неумирающая, неразрушимая Италия» («Чувство Италии», 1915) [1. С. 368-369]. Не одно поколение русских и итальянских ученых занималось изучением исторических форм и, главное, духовной сути этого взаимного тяготения. Благодаря им мы не только хорошо представляем себе общие культурно-эстетические смыслы, которые пронизывают русскую рецепцию Италии, но и можем выделить многие ключевые концепты, очень часто имеющие пространственную привязку. Рим, Венеция, Флоренция, Неаполь оказались в отечественном сознании локусами миромоделирующего значения, позволяющего ощутить саму Италию своеобразным космосом, системой планет-городов, где местные различия очень важны в симфонии целого. Современная имагология, активно выходящая в последние десятилетия с плана общенационального на уровень региональный, дала прочную методологическую основу для изучения итальянских «городских текстов» и восполнила многие лакуны в исследовании русской рецепции Рима, Венеции, Флоренции (из ключевых работ [2, 3]). Книга Ольги Лебедевой и Александра Янушкевича впервые позволяет осмыслить значение Неаполя как предмета активной культурологической рефлексии русских писателей XVIII - начала XX в.

Монография выросла из многолетних историко-литературных наблюдений авторов и стала результатом сотрудничества с итальянскими учеными-русистами. Ее издание в Салерно в серии «Europa Orientalis» под редакцией Марио Капальдо и Антонеллы Д’Амелия, главы Международного научно-исследовательского центра «Rossia-Italia» - «РоссияИталия», служит образцом плодотворного взаимодействия национальных научных школ и само является новым фактом межкультурного итальянско-русского диалога. Последнее выразительно подчеркивает приложение, созданное усилиями исследователей Неаполитанского университета «L'Orientale» и Центра культуры и истории Амальфи, куда вошли библиография русской литературной неаполитаны XVII-XX вв. а также каталоги художественных выставок и перечень живописных произведений, посвященных городу и его окрестностям. Приложение предваряет краткая, но содержательная статья Донаты Ди Лео, професcopa Университета «L'Orientale» о сути поисковой работы и объеме выявленных материалов неаполитанских впечатлений русских писателей и художников за более чем трехвековой период. Библиография позволяет наглядно прочертить векторы непресекающегося отечественного интереса к Неаполю и служит ценнейшим пособием для любого ученого, обращающегося к данной теме. 
Книга Ольги Лебедевой и Александра Янушкевича имеет не только историко-литературное, но и теоретико-методологическое значение, плодотворно развивая положения современной имагологии. В течение долгого периода становления от трудов Ж.-М. Карре до Г. Дизеринка эта научная дисциплина оперировала интегральными категориями, позволяющими зафиксировать более или менее цельный образ рецепции «чужого» культурного мира. Ее объектом становился пласт обобщающих смыслов и форм, тяготеющих к архетипичности, к закреплению устойчивого представления о той или иной национальной ментальности и ее культурно-историческом воплощении. В подобной интерпретации имагология становилась наукой о национальных мифах и стереотипах, что ощущается до настоящего времени, примером чему может служить энциклопедический труд «Imagology: the cultural construction and literary representation of national characters: a critical survey» [4]. Активное привлечение в последнюю четверть века конструктивистских методов постколониальных, мультикультурных исследований, изучения национальной идентичности не изменило, в сущности, ориентацию на сферу обобщающих культурных смыслов.

Предметом внимания томских ученых, отталкивающихся от концепции Н.Е. Меднис, выступает скорее структура имагологического образа, ее уровни и составляющие, связанные системными отношениями. Образ национального «другого» при таком подходе складывается не столько из интегральных мифов-концептов, сколько из скоординированной рецепции дифференцированных культурных примет. Природно-ландшафтный план здесь отражается в зеркале антропологии, в восприятии местных нравов, проецируется на национальную или региональную историю и социально-политические контексты, обрастает системой продуктивных локальных сюжетов, обретает опору на персонажную систему и воплощается в миромоделирующих тропах. Изучение подобного образа требует, конечно, больших историко-литературных разысканий, поскольку сложная структура имагологического конструкта находится в постоянном движении и на протяжении даже полувека рецептивной истории может существенно измениться, выдвигая на первый план то одни, то другие уровни или элементы.

Ольга Лебедева и Александр Янушкевич сосредоточили свое внимание на эпохе становления образа Неаполя в русской словесности. Именно в XVIII - первой половине XIX в. определились и обрели устойчивость основные слагаемые отечественной неаполита- 
ны. В последующие периоды ее геопоэтика, антропология, культурноисторический канон будут подвергаться активному переосмыслению под влиянием новых художественных парадигм, но никогда не потеряют связи с традицией Константина Батюшкова и Василия Жуковского, Александра Пушкина и Николая Гоголя. Пожалуй, образ Неаполя наиболее отчетливо показывает, насколько глубоко романтические контексты, обогатившиеся опытом раннего реалистического анализа, оказались вплавлены в русскую рецепцию «возрождающей душу» Италии. Рост социальной критичности, углубление культуро- и историософской рефлексии, перипетии политических отношений двух стран не изменили восприятия Неаполя как в первую очередь мифогенного локуса, воплощения бурной энергии жизни, обретающей особую ценность перед лицом возможного уничтожения. Этот образ прекрасного неаполитанского залива рядом с огнедышащим вулканом является лейтмотивом в монографии и неизменно возникает при обращении к любым текстам русской неаполитаны.

Художественно выстроенная композиция книги позволила авторам контрастно соединить два полюса рецепции, показав цикличнокольцеобразный характер неаполитанского текста через сюжет петровского стольника Петра Толстого, совершившего одно из первых литературных путешествий в древний город и сыгравшего роковую роль в судьбе царевича Алексея Петровича. Пристальное внимание к семантике, к тонкому миру смыслов, характерное для всей монографии в целом, открывает в путевых записках Толстого фундаментальную интенцию, определившую русское «чувство Неаполя». «Чудный», «дивный», «удивления достойный» город предстает в восприятии человека Петровской эпохи очарованной землей, полной красоты и овеянной духом сказки. Но уже следующая глава, посвященная одному из загадочных сюжетов русской истории - пребыванию царевича Алексея Петровича в замке Сант-Эльмо и роковому возвращению его к отцу на пытку и смерть, погружает нас в атмосферу экзистенциального трагизма. В романе Дмитрия Мережковского «Антихрист (Петр и Алексей)» неаполитанский эпизод соединяет ощущение чуда с мортальной семантикой, питаемой природными (извержение Везувия, сирокко) и культуролого-мифологическими контекстами (следы ушедшей языческой Античности).

Это буйство жизни на краю смерти выразительно демонстрирует различие национальных характеров. В последующих главах книги, в особенности посвященных антропологии неаполитанского текста, ав- 
торы книги неоднократно останавливаются на описании местных нравов у Ф.П. Лубяновского, В.Б. Броневского, Н.С. Всеволожского, Н.И. Греча, М.П. Погодина, А.М. Зилова, В.Ф. Одоевского. Их воплощением чаще всего становится колоритный образ лаццарони - беззаботного неаполитанца, праздного, ленивого, плутоватого, бедного, но неизменно жизнерадостного. Его нечувствительность к соседству грозного вулкана, ежеминутно грозящего гибелью, поражает русских путешественников. Для них близость жизни и смерти - источник совершенно иных, трагических переживаний, повод для экстатического «упоения в бою, и бездны мрачной на краю». Поэтому, пожалуй, Неаполь так родствен русской душе и так важен для нее - как школа иного экзистенциального восприятия, не болезненного, но возрождающего и примиряющего.

Недаром, очевидно, самые психологически тонкие расследования, а именно такой характер имеют многие разделы книги, посвящены биографическим аспектам русской неаполитаны. Их лейтмотивом становится итальянская пословица «Vedi Napoli e poi muori» (Увидеть Неаполь и умереть), точно передающая эту чрезмерность жизненной энергии, ее напряженность - и освобождение от страха смерти. Для Константина Батюшкова, Евгения Баратынского, Николая Гоголя пребывание в Неаполе становится своеобразным примирением с жизнью в конце долгого пути, после создания главной книги-завещания. Авторы монографии чутко вписывают экзистенциальную динамику неаполитанских переживаний в космологическую структуру городского локуса, где вечный природный Элизиум органично совмещается с напоминанием о бренности человеческих свершений (Байя, Помпеи, Геркуланум) и близостью к стихиям разрушения (Везувий, Елисейские поля). Неаполитанский катарсис, однако, требовал определенной настроенности души, органического мировосприятия, как в случае Василия Жуковского, для которого пребывание в городе ожившей Античности стало ступенькой от романтического спиритуализма, воплотившегося в переводе гетевской «Mignon» и шиллеровской исторической элегии «Помпеи и Геркуланум», к эпическому постижению жизни. Батюшкова, Баратынского, Гоголя Неаполь не спас, он «обострил ощущение внутреннего ада и духовной исчерпанности» [5. С. 174].

Книга Ольги Лебедевой и Александра Янушкевича приближает нас не только к пониманию индивидуальной творческой психологии, но и к постижению исторической динамики в литературном осознании Неаполя. От «Путешествия стольника П.А. Толстого» конца XVII в. к документальным, одическим и романным образам XVIII столетия 
(Н.А. Демидов, Ф.А. Эмин, Г.Р. Державин), многочисленным травелогам, лирике и прозе сентиментально-романтической эпохи, к иронии «Сенсаций и замечаний госпожи Курдюковой за границею, дан л'этранже» И.П. Мятлева и эпичности «Писем из Венеции, Рима и Неаполя» В.Д. Яковлева вплоть до символистской рецепции Д.С. Мережковского простирается преемственная связь форм культурнохудожественного восприятия. Она не является предметом отдельного анализа, однако выступает фоном любых конкретных наблюдений и разборов. Ее внутреннюю логику определяет «присвое-ние» Неаполя, который шаг за шагом становится неотъемлемым элементом русской картины мира и, более того, приобретает миромоделирующее значение. Прямолинейные сравнения итальянского города с Москвой у Петра Толстого уступают место культурной эмблематике Федора Эмина и Гавриила Державина, встраиваемой в характеристику «своих» событий или персонажей, а им на смену идет осознание самоценного геопоэтического колорита, превращающего Неаполь в очарованное «там» русских романтиков. Блестящий анализ пятнадцати переводов гетевской «Mignon» и лирической неаполитаны 18201860-х гг. наглядно показывают, как органично локальные приметы Южной Италии, ее природа, древняя культура и жизнелюбивая современность приобретают под пером жителей Севера универсальномифологическое звучание. «Космос» города-мира оказывается настолько обжит, настолько сроднится с семантикой ключевых концептов русской культуры, что даже для поэта, никогда его не видевшего воочию, как Пушкин, неаполитанские мотивы становятся незаменимым инструментом в реализации художественных замыслов.

В этом плане пушкинская неаполитана исключительно важна в архитектонике книги, она демонстрирует тонкое сплетение очевидного и подразумеваемого, когда Неаполь может даже напрямую не упоминаться в тексте, но сложившаяся в русском культурном сознании и собственно пушкинской семиосфере система взаимосвязанных образов оказывается настолько прочной, что позволяет ее актуализировать через намек, ассоциативную отсылку. Виртуозно построенные четыре этюда о политической, природно-ландшафтной, психологической и мифопоэтической семантике неаполитанских мотивов у Пушкина поражают сочетанием тщательной аргументации, привлечением максимально возможного количества фактов о круге чтения, осведомленности, биографических обстоятельствах, творческой истории произведений с очень смелыми гипотезами о возможных контекстах 
того или иного сюжета или образа. Такова, например, неаполитанская привязка пушкинского сюжета о Клеопатре, обнаруживающего связь с легендами о королеве Джованне I и Джованне II и ассоциациями с ними у неаполитанских путешественников (Ш. Дюпати, Ф. Лубяновский) образа английской королевы Елизаветы. Контекстуальный анализ вовлекает в эту сферу не только пушкинский сюжет убийственной любви в «Бахчисарайском фонтане», но и позднейшие лермонтовскую балладу «Тамара», элегию Евдокии Ростопчиной «Еще о Неаполе» и стихотворение Аполлона Майкова из «Неаполитанского альбома», испытавшие влияние интерпретации уже самого Пушкина.

Подобный уровень «одомашнивания» неаполитанских мотивов не мог не привести уже к середине XIX в. к преодолению романтической трансцендентности. Симптоматично, что Ольга Лебедева и Александр Янушкевич неоднократно в разных разделах книги обращаются к соответствующим фрагментам «Сенсаций и замечаний госпожи Курдюковой за границею, дан л'этранже» Ивана Мятлева, где героиня совершенно фамилиарно, без какого-либо пиетета относится к местным достопримечательностям, воспринимая их как что-то само собой разумеющееся. В этом госпожа Курдюкова оказывается поразительно сродни пресловутым лацицарони, для которых даже огнедымащий Везувий не более чем живописная иллюминация к вкусному ужсин. Ей, как и другим русским путешественникам второй половины XIX в. гораздо интереснее человеческий универсум, предстающий в Неаполе в буйном, порой контрастном разнообразии проявлений. Так, кодой всей книги закономерно становится анализ «Италии. Писем из Венеции, Рима и Неаполя» В.Д. Яковлева, в которой авторы тонко отмечают черты универсализма, приметы эпически-гомеровской картины мира, органично соединяющей природное, мифологическое, историко-культурное начало с вниманием к реалистическим, крупно выписанным деталям живой неаполитанской повседневности.

Пристальное внимание к исторической поэтике, к эволюции художественного постижения Неаполя прочно увязано в книге с анализом имагологической структуры. Нельзя не согласиться с авторами в том, что опорным уровнем русской неаполитаны выступает мифопоэтика: настолько насыщен локус знаковыми природными объектами, памятниками Античности и Средневековья. Более чем стостраничной главы оказывается едва достаточно, чтобы познакомить читателя с рецепцией лишь самых мифогенных топосов и персоналий - Везувия, гробницы Вергилия, Капри. Каждый из них порождает разветвленный интер- 
текст с массой индивидуальных поэтических вариантов, скоординированных, однако, уникальным по своему характеру универсализмом. Ад и рай, жизнь и смерть, древность и современность предстают в Неаполе элементами единого целого. Здесь каждый образ легко обрастает массой проекций: огнедышащий Везувий превращается в политическую метафору жизни на вулкане, столь популярную у русских авторов эпохи бурных исторических движений, гробница Вергилия вызывает рефлексию о месте поэта в веках, а развалины дворца Тиберия на прекрасном Капри становятся источником насыщенного историософского текста.

В последующих главах природно-ландшафтное и сюжетноперсонажное пространство неаполитаны продолжает расширяться, обнаруживая поразительное богатство. Животрепещущая политическая современность входит в круг русской рецепции через сюжет о карбонариях и журнальные известия о неаполитанской революции 1820-1821 гг. «Вестник Европы» и «Сын Отечества» знакомят читателя с деталями событий, которые ассоциативно смыкаются с отечественными политическими движениями эпохи «гражданской экзальтации» и бурными эстетическими полемиками, рождая феномен «литературного карбонаризма». Разделы о Батюшкове, Баратынском, Жуковском, Пушкине и Гоголе рисуют выразительную панораму города, где Капри и Сорренто, виды Неаполитанского залива, Помпеи и Геркуланум, погруженная в воду Байя, Поццуоли с его античными развалинами и кратером Сольфатара, Кумы и Аверно, легендарный вход в Аид, порождают собственные микросюжеты, причем не только литературные, но и живописные. Этот параллелизм слова и изображения отзывается в графике «Неаполитанского альбома» Василия Жуковского, хранящегося в РНБ, рисунки из которого опубликованы в приложении к соответствующему разделу книги.

Не менее насыщенным предстает в книге и персонажный состав русской неаполитаны. Величественную фигуру Вергилия здесь органично дополняет Тассо, чья судьба занимает Лубяновского и Батюшкова, Вяземского и Пушкина, римские императоры Тиберий и Август соседствуют со средневековыми (Джованна I и II) и современными авторам королями (Фердинанд IV, королева Каролина), в неаполитанское пространство помещает Владимир Одоевский архитектора Джамбаттиста Пиранези, а Пушкин своего импровизатора из «Египетских ночей». Индивидуальные сюжеты, где реально-историческое органично переплетается с художественным воображаемым, накла- 
дываются на коллективные портреты и типажи из местного быта, закрепляя в русском восприятии образ бурно текущей вольной жизни.

Тщательно прорисованный имагологический образ Неаполя, раскрывающийся в системе своих составляющих и массе авторских художественных вариантов, - фундаментальный вклад томских ученых в мировую итальянистику. Огромный историко-литературный материал, филигранность аналитических разборов, сочетание строгой аргументированности и смелых гипотез, глубина теоретической мысли, наконец, увлекательность изложения делают книгу Ольги Лебедевой и Александра Янушкевича большим научным событием, интересным не только для академического сообщества, но и для широкой публики, а прекрасное полиграфическое исполнение, обилие живописных иллюстраций и удобство указателей свидетельствуют о высоком мастерстве авторов и редакторов и их уважении к читателю.

\section{Лuтература}

1. Бердяев Н.А. Философия творчества, культуры и искусства. М., 1994. Т. 1.

2. Меднис Н.Е. Венеция в русской литературе. Новосибирск, 1999.

3. Гребнева М.П. Концептосфера флорентийского мифа в русской словесности. Томск, 2009.

4. Imagology: the cultural construction and literary representation of national characters: a critical survey / Ed. by M. Beller and J. Leerssen. Amsterdam; New York, 2007.

5. Лебедева О.Б., Янушкевич А.С. Образы Неаполя в русской словесности XVIII первой половины XIX веков / ред. М. Капальдо, А. Д’Амелия. Салерно, 2014.

“... THE ETERNAL， UNDYING， INDESTRUCTIBLE ITALY” (BOOK REVIEW: LEBEDEVA, O.B. \& YANUSHKEVICH, A.S. (2014) OBRAZY NEAPOLYA V RUSSKOY SLOVESNOSTI XVIII - PERVOY POLOVINY XIX VEKOV [IMAGES OF NAPLES IN THE RUSSIAN LITERATURE OF THE EIGHTEENTH - FIRST HALF OF THE NINETEENTH CENTURIES]. ED. BY M. CAPALDO AND A. D'AMELIA. SALERNO)

Imagology and Comparative Studies, 2015, 1(3), pp. 177-186. DOI: 10.17223/24099554/3/11

Kiselev Vitaliy S. Tomsk State University (Tomsk, Russian Federation). E-mail: kvuliss@mail.ru

Keywords: the history of Russian literature, imagology, Italy, Naples, the ItalianRussian literary connections.

The article is devoted to the research conception of a new monograph by Olga Lebedeva and Alexander Yanushkevich about Russian literary reception of Naples. The attention is focused on the original methodological approach to the reconstruction of imagological representation. The significance of the dominants in mythopoetics, nature and landscapes, anthropological and cultural-historical perspective of the Russian Naples experience of the 18 th - early 20 th centuries the authors identified is evaluated. 


\section{References}

1. Berdyaev N.A. Filosofiya tvorchestva, kul'tury i iskusstva. M., 1994. T. 1.

2. Mednis N.E. Veneciya v russkoj literature. Novosibirsk, 1999.

3. Grebneva M.P. Konceptosfera florentijskogo mifa v russkoj slovesnosti. Tomsk, 2009.

4. Imagology: the cultural construction and literary representation of national characters: a critical survey / Ed. by M. Beller and J. Leerssen. Amsterdam, New York, 2007.

5. Lebedeva O.B., Yanushkevich A.S. Obrazy Neapolya v russkoj slovesnosti XVIII pervoj poloviny XIX vekov / Red. M. Kapal'do i A. D'Ameliya. Salerno, 2014. 